\title{
農業藥剂在我國農業生產中的重 要性及其發展的趋势
}

黄瑞緰

(北京嶨棠大学)

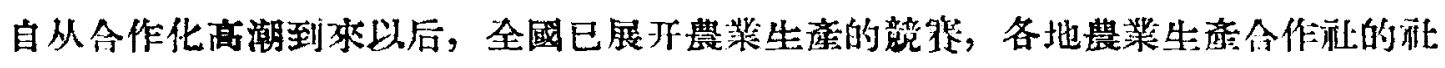

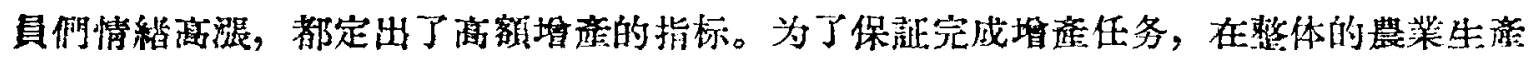
措施中，防治病虫害占有極重要的位置。缺之这个环節，将会使其他農亲指施也不能达

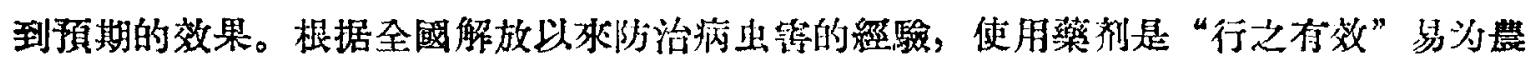

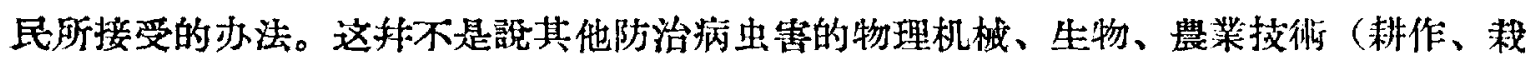
培、改变环境等)等方法不重要。虽然只有各种方法的綜合使用少能獲得最㴖意的絬果,

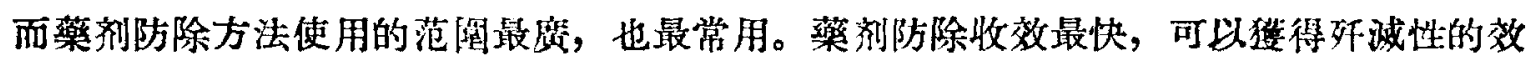
果, 也最容易接受机械化。

今年布尔加䁇同志在苏共第二十次代表大会上所作的关于1956-1960年苏联發展 国民經济第六个五年計划的指示的报告中指出, 在化学工業方面, “必須生逢新的效力

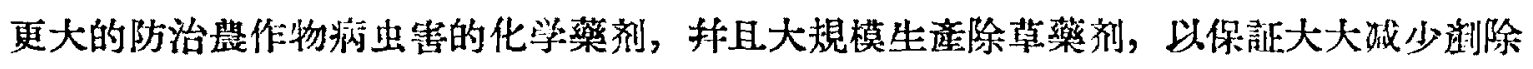

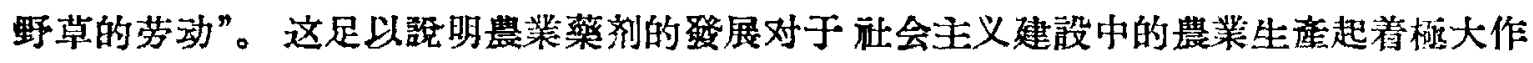
用。

自第二次世界大战以后, 有关農業䒚剂科学的發展極快, 各种各样的新型菜剂不断 出現于國际市埸。这些藥剂可以單用, 也可以混用。如果我們选擇得当, 几乎任何利害 虫都可以用䒚剂防除; 除某些病毒或細菌病外，大部分的病整也可以用菜剂防除。

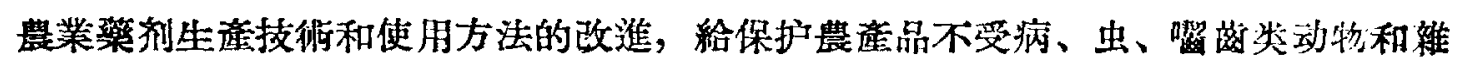

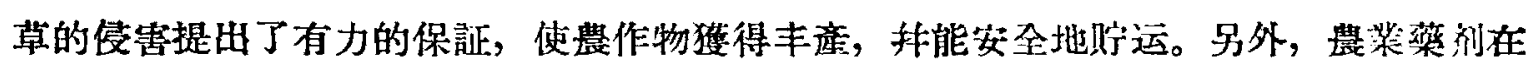
國防建設、改善妚壏街生和保健上，也具有重大的意义。

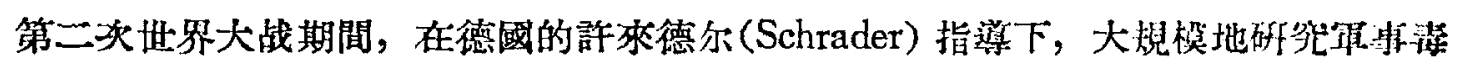

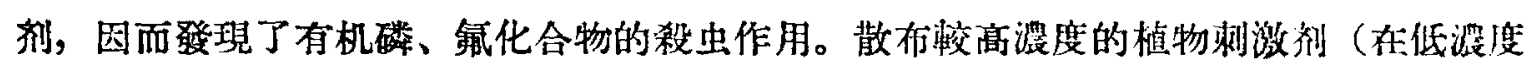
下可以作选擇性的除菱剂，如 2,4-D、2,4,5-T、I P P C 之类）也可以毁诚大而程的

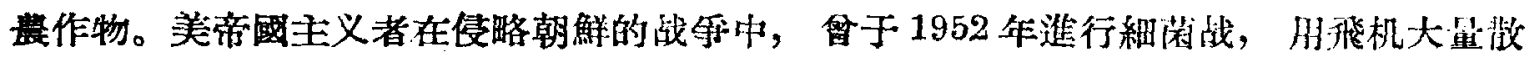

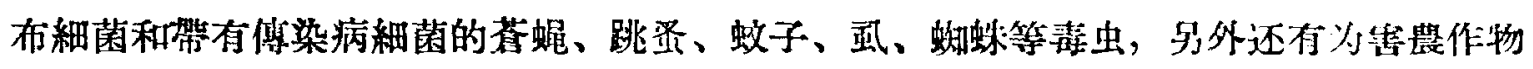
的害虫和病菌，在第二炏大战中也在德國散布过馬鈴薯甲虫。汾珹这些散存的害虫和病 菌, 只有及时地使用農業䒚剂才能收到良好的防御效果。我國政府为了践少精食的损失,

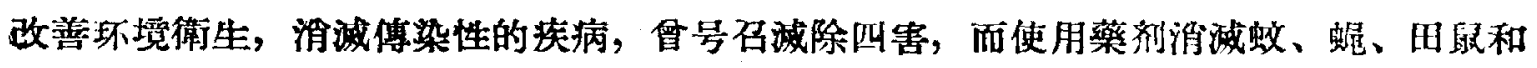


家鼠是悢济而有效的办法。

現在國家正在制定科学远景規划，像農業菜剂这样的一个重要的項目必会得到重悓， 若干科学家們也必将按照規划参加有关農業藥剂的实际工作。我今简略地介紹農業藥剂 科学在國內外發展的情况，持提出对于今后發展这一門科学的方向和措施，供作請者参 将。

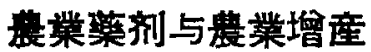

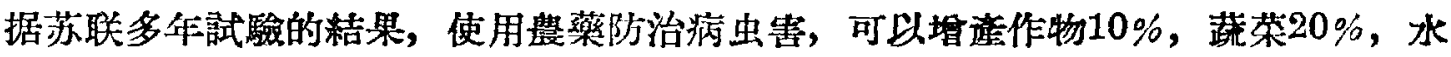

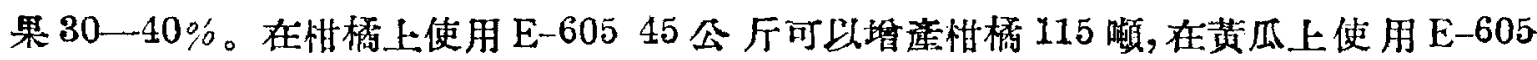

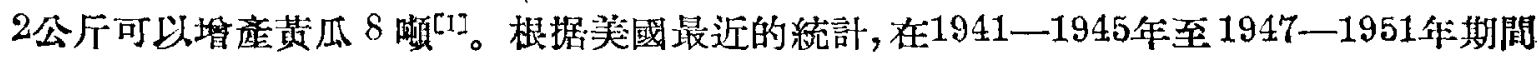

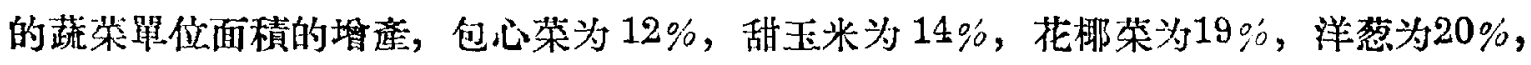

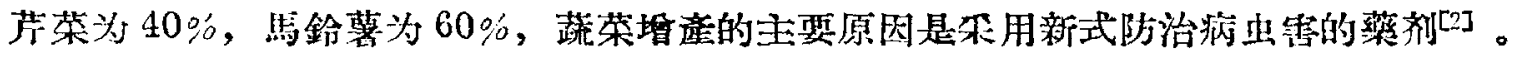

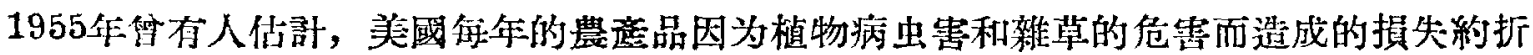

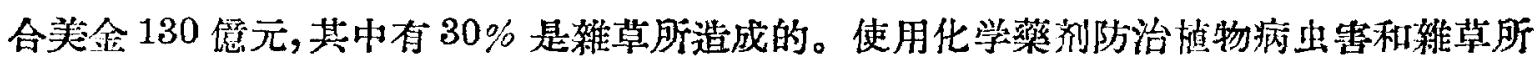

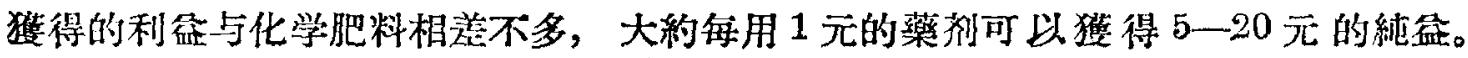

我國目前仍然是一个病虫害比较嚴重的國家。在我們的國土上，海年几乎有 $50 \%$ 的

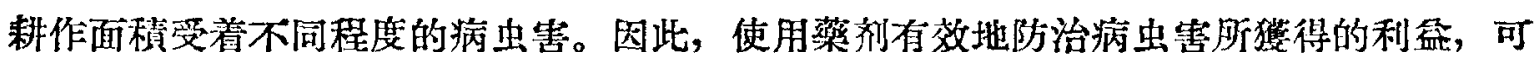

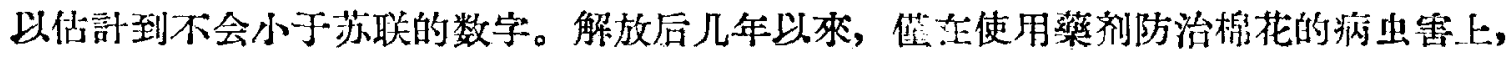

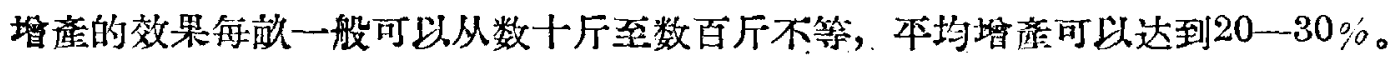

\section{農業藥剂在國外㓎展的情况}

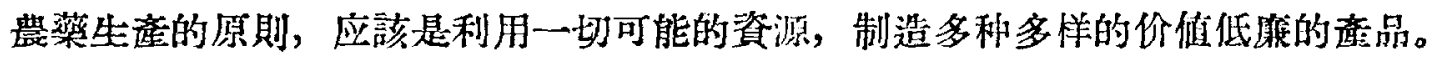

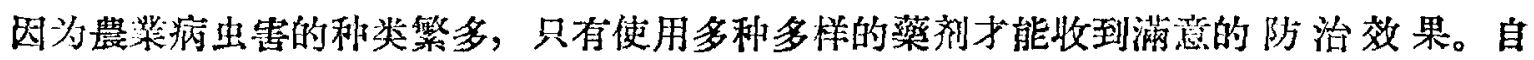
1932年起，苏联已完全不需要進口農藥了。根据只有多种多样的藥剂品科互相补光調济

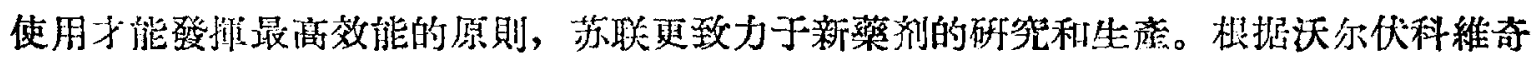

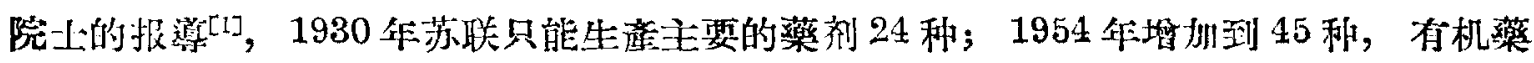

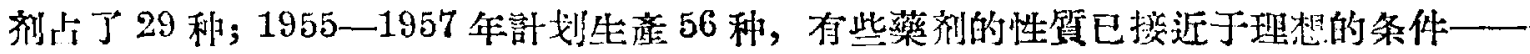

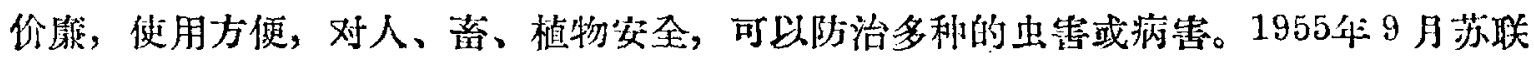

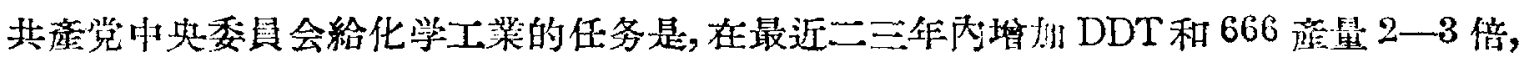

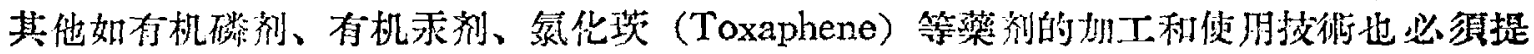

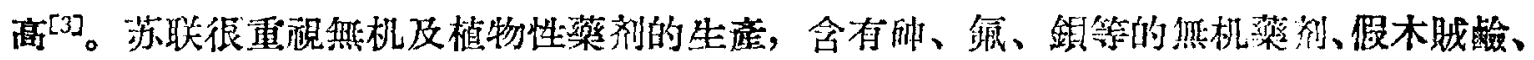

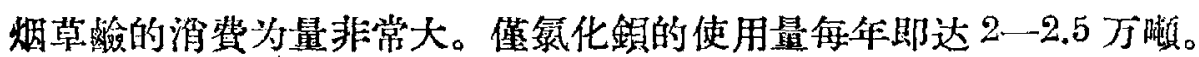

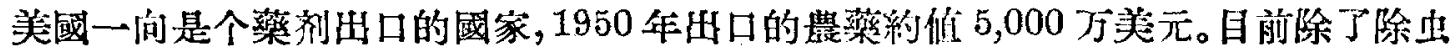

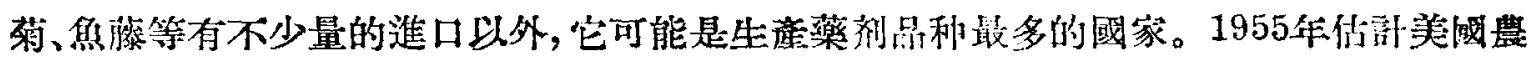

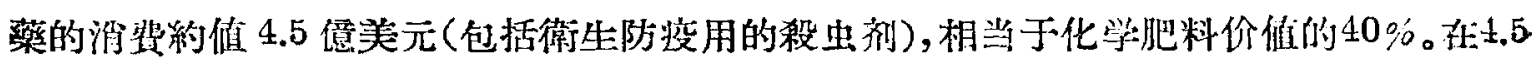

[1] C. H. 沃尔代科維奇: 化学与㷞業, 份末酸表。

[2] Griffin, E. L.: J. Assoc. Offic. Agr. Chemists, 38:35(1955).

[3] Никифоров, А. М.: Земпевелие, 1955(10):88. 


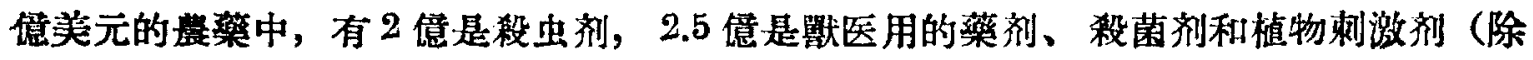

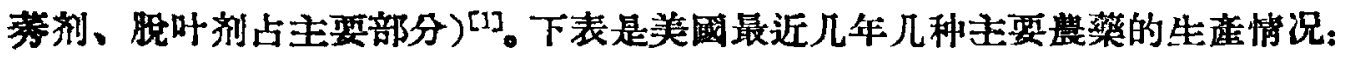

\section{美國最近几年本每年主要莀药的消費量}

以万磅为單位，未加填充料的工莱品 $[2,3$, 亿]

\begin{tabular}{|c|c|c|c|c|c|}
\hline 品 & 洞 量 & 期 & 种 & 消 量 & 时 \\
\hline $666(12 \% \alpha y)$ & 9,500 & $1951-1952$ & DDT & 8,500 & $1951-1952$ \\
\hline 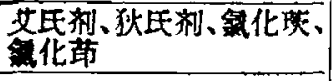 & 9,100 & $1951-1952$ & 砷酸銛 & 4,500 & $1931-1952$ \\
\hline 砷酸鍇 & 3,000 & $1951-1952$ & $E-605$ & 700 & $1951-1052$ \\
\hline TEPP & 140 & 1951 & $\begin{array}{l}\text { 有机台成䄫螨利(不白 } \\
\text { 括 } \mathrm{E}-605 \text { 或 TEPP) }\end{array}$ & 200 & $1951-1952$ \\
\hline 魚蟼桹 & 700 & $1951-1952$ & 姻草貔 & 500 & 1350 \\
\hline 除虫㐘䓯 & $8-10$ & $195 \tilde{5}$ & 硫酸銅 & 10,500 & $19 ; 1-1958$ \\
\hline 研黃 & 48,300 & $1950-1951$ & 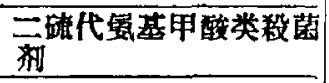 & 2,000 & $1951-1052$ \\
\hline 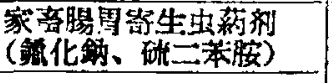 & 500 & $1951-1952$ & $2,4-D$ & 2,800 & $1951-1052$ \\
\hline $2,4,5-\mathrm{T}$ & 600 & $1951-1952$ & & & \\
\hline
\end{tabular}

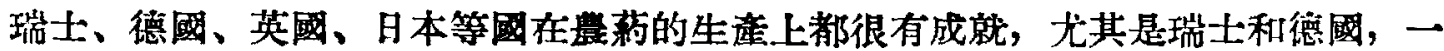

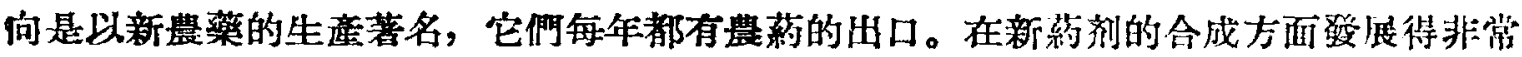
迅速，新的、性罂近于理想的商品不断出現于國际本場。1945年为有机合成获剂發展的 起始点，維 DDT、666 之后，有机氯化合物有狄氏剂（Dieldrin）、艾氏剂（Aldrin）、异狄 氏剂(Endrin)、异艾氏剂 (Isodrin)、氯化茨(Toxaphene)、氯化菠烯（Strobane）、丙闻 (Prolan)、丁蘭 (Bulan) 等等出現。这些葯剂除最后丽利外都不是以染为原料的，它們 和 DDT 或 666 比較都各有特長，不美上下。

自第二次大战以后，有机磷剂的發展最为笑出。最早出现的有机磷剂当推 TEPP 和 E-600, 其后則为 E-605。目前 E-605 仍为最优秀的耓虫葯剂之一，但它具有对于人亩 强烈的毒害作用。最近在减低有机磷剂对于人畜毒害的研穵上有很大的成能，已垁有几 种很成功的菜剂出現于市場。以下为新發現的几种有机磷剂对于高等动物表力的比较, 以E-605 为标准:

$\mathrm{E}-605$

甲基 $E-605$

Bayer22/190 (Chlorothion)

G-24480 (Diazinon)

4049(Malathion)
$2-5$ 嶨克/公厅体更, 致死中民

毒力等于 E-605 的为

毒为等于 $E-605$ 的 $1 / 200(1,500$ 年克/公厅体直, 致死中最)

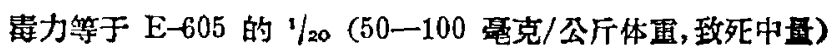

毒力等于 E-605 的 $1 / 50-1 / 100$

[1] Messing, R. R.: Agr. Chem. 10(8):47(1955).

[2] McAlister, Jr. L. C., H. H. Shephard: J. Econ. Entomol. 46:370(1953).

[3] Shephard, H. H.: Agr. Chem. 7(4):73(1952).

[4] Stoḍdard, R. R.: Soap, 32(1):124(1956). 
后三者对于人畜已程达到相当安全的程度, 手且, 已有可能作为家畜的內服㸓, 治療

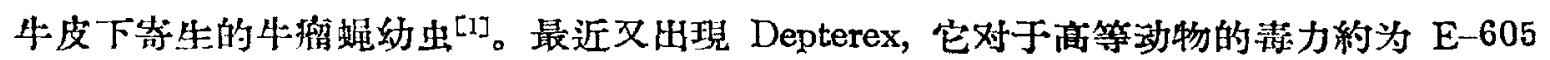
的 $1 / 100$, 防治家蛇或咀嘌口器的害虫特別有效 ${ }^{[2]}$ 。由此可胃, 在有机磷殺虫剂的研究中, 追求对于人畜更为安全, 而程虫效力近于 E-605 的化合物还有很大的可能性。

內吸殺出藥剂的实际应用在殺虫藥剂使用方式上为一重大發展。早于1941年，辟隶 德尔就發現了 OMPA 的內吸殺虫作用, 1948年又合成了 E-1059(Systox)和甲基 1059。

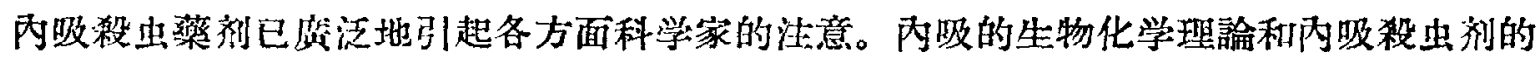
应用, 都在迅速發展中。甲基 1059 对于高等动物的毒力約为 E-605 的 $2 / 10$, 而对于防 治蚜虫、螨类害虫的效力相等或有过之，且使用方便，藥效長久。最近已省定使用甲基 1059防治果樹或蔬荣上的害虫对于人畜是安全的 ${ }^{[3,4]}$ 。

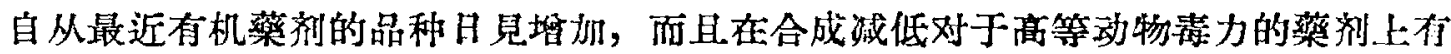

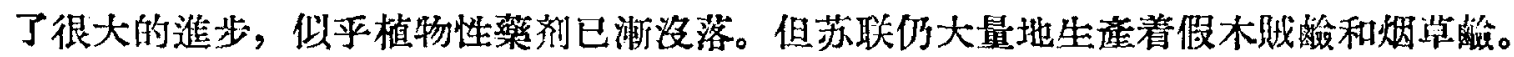

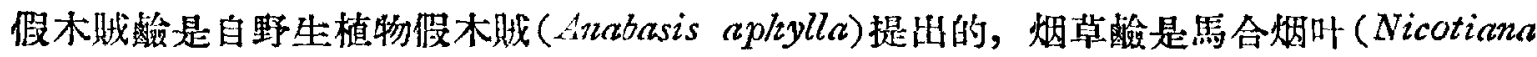
rastica) 制造紙烟的副道品，因此成本低廉。美國副烟酹在 1940-1950 年期間每年消

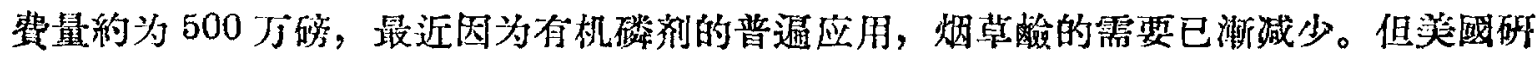

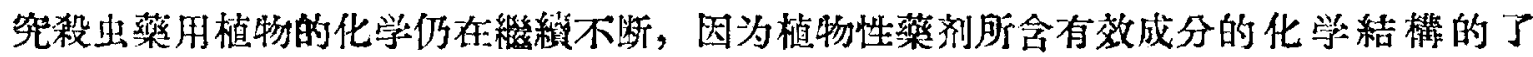
解，对于有机藥剂合成方面有指拳作用。他們呼究除虫菊素的化学結棈式獾得成功，而

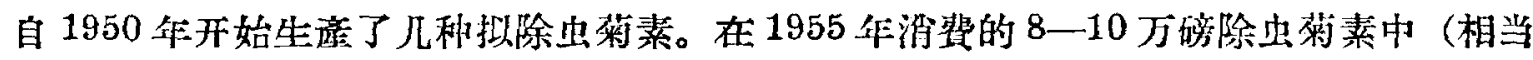
于除虫获花 800-1,000 万磅)，合成的約占一牛。除虫菊素一类的化合物在防治获媒察 虫上仍为最优秀的藥剂。研究天然除虫菊素的增效剂—芝確素, 而合成了多利洲有 2,4一次甲等二氧苯环的衍生物。此类增效剂的使用節省了大量的除虫料素。在研究紫云

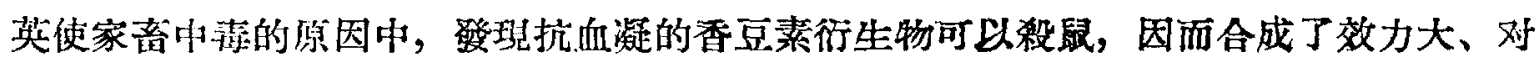
人畜比较安全的殺鼠剂“瓦招林”(Warfarin)。

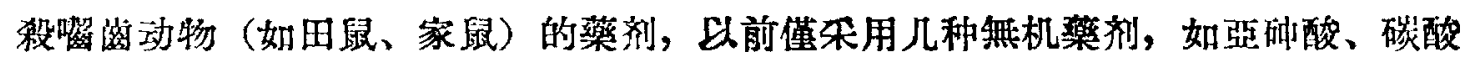
鋇、黃磷之类，这些藥剂都有很大的缺点，最近已不常用。硫酸釷为治煤厂的副差品，

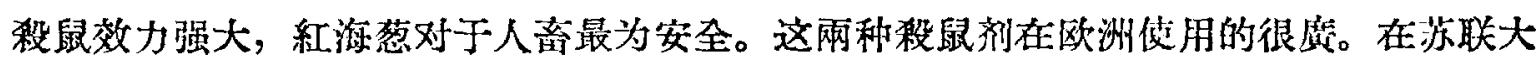

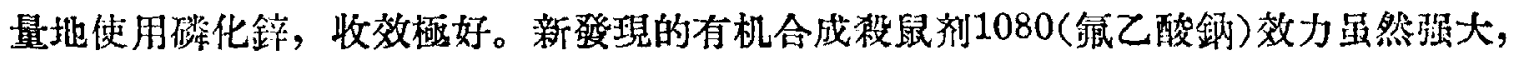

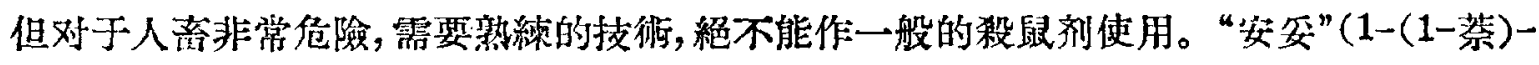
-2-硫服) 是一个效力比较好而对于人畜安全的藥剂，但是鼠奖在一次取食低于致死剂最 时会產生抗力，而且致死的剂量因气温而有改变。自 1950 年以后，合成粉鼠剂“瓦非

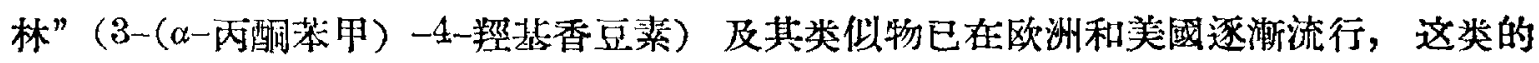
樂剂有抗血凝作用, 是一个殺鼠效力强大, 对于人畜比较安全的藥剂。

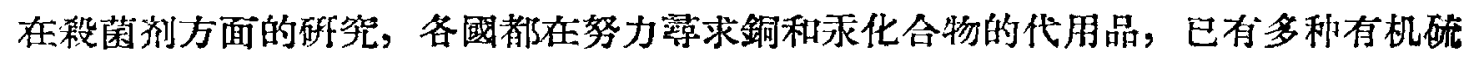

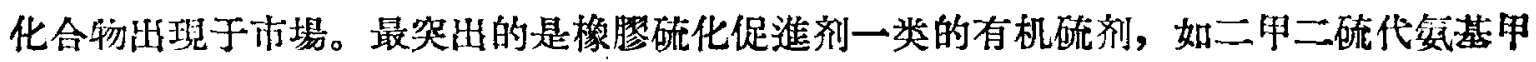

[1] McGregor, W. S., R. D. Radeleff, R. D. Busland: J. Econ. Entomol. 47:465(1954).

[2] Lomez, W., A. Henglein, G. Schrader: J. Am. Chem. Soc. 77:2554(1955).

[3] von Rümker, R.: Agr. Chern. 10(3):41(1955).

[4] Fjelddalen, J.: Höfchen-Briefe (Eng. Ed.),8(1):1(1955).

6 月号

科学道报 


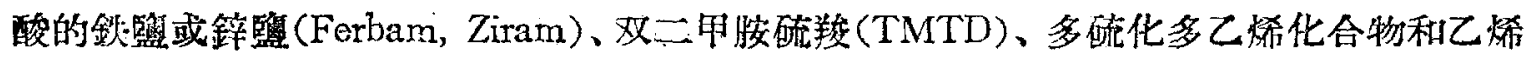

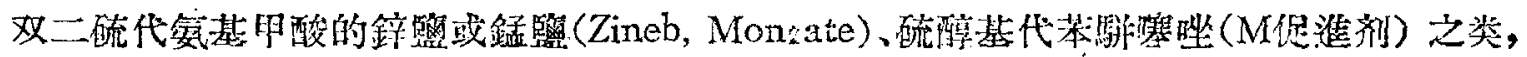

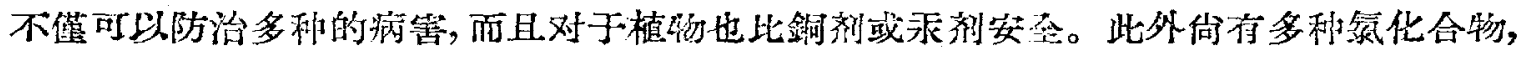

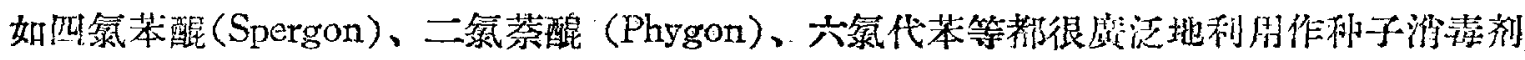

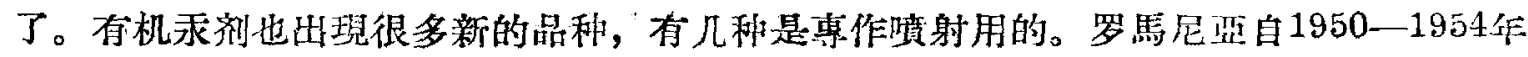

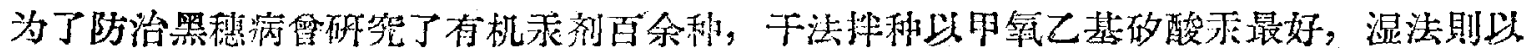

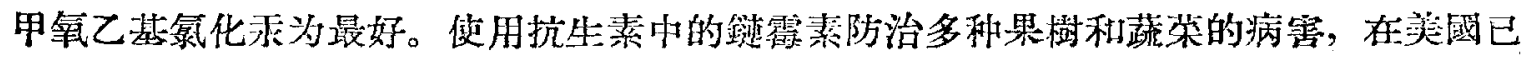

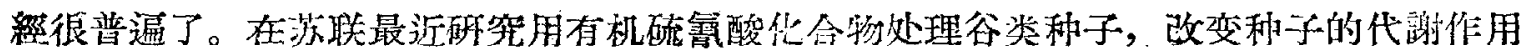

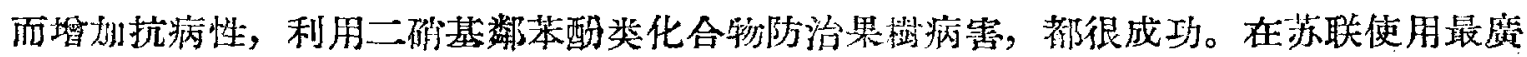
泛的种子消瑇剂是甲醭。

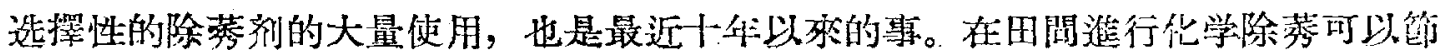

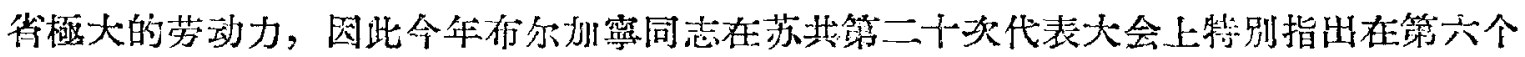

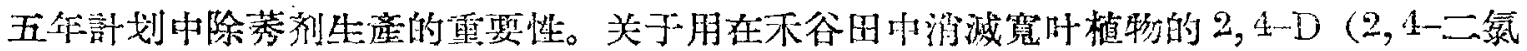

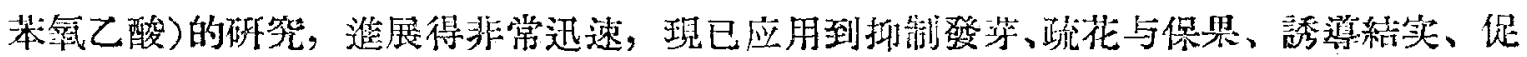
淮生根、刺激生長等方面了。类似 2, 4-D 而特别对消減灌木有效的 $2,4,5-\mathrm{T}(2,4,5-$ 三 氯苯氯乙酸) 和消娍單一叶菜草特別有效的 IPPC (苯甲氨酸异丙酯) 的使用也在开展

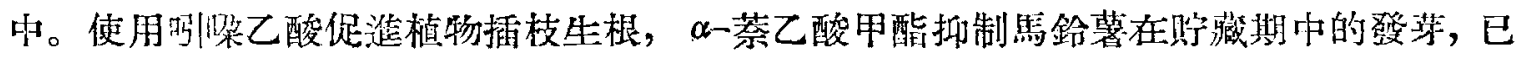

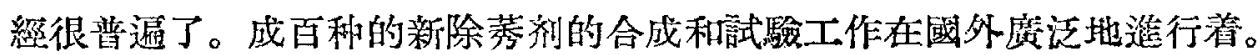

堆效剂自从使用在除虫菊素上獲得成功之后, 应用范国已大为厦大, 給樂剂混合使 用提出新的方向。最近發現执已应用到实踐中去的互相增效混合使用的㩰制已有多种， 例如乙烯双二硫代氮基甲酸監类与無机鈳剂混合使用可以提高殺菌效力，比單用效力的

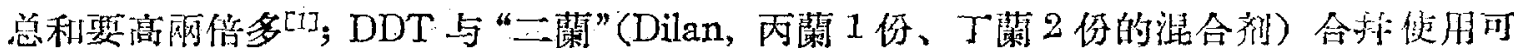

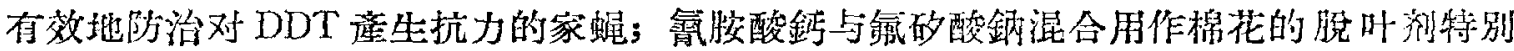
有效 ${ }^{[}$]。化学肥料、除药剂、殺虫剂或殺菌剂的混合剂在美國已緸商品化了。虽然这种 混合剂在效喿上难以作到十全十美，但是在某一地区，針对某种特别要求和条件使用一 定混合比侧的混合剂，可以節省很大的荢动力。

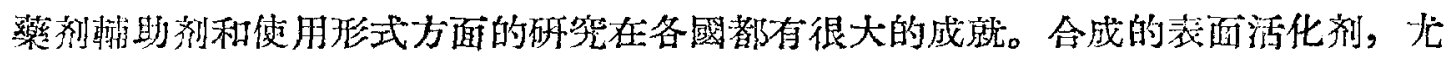

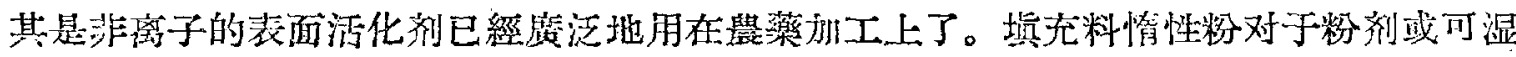

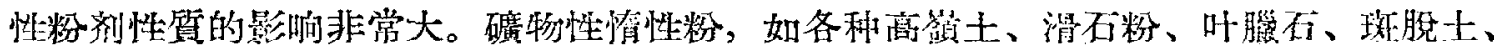

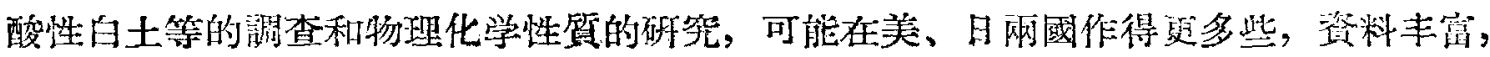

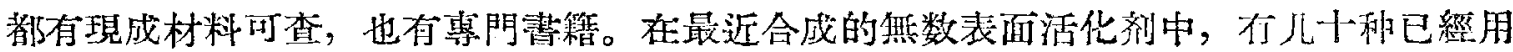

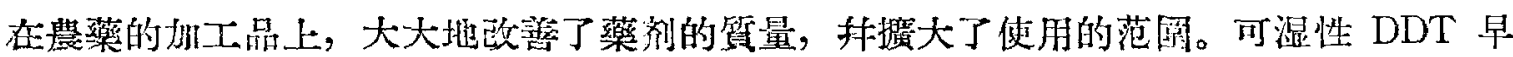

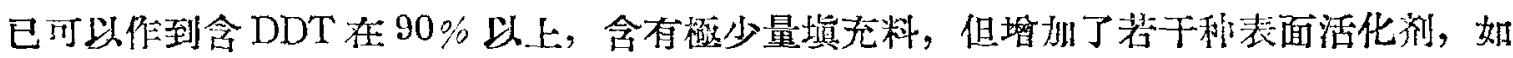

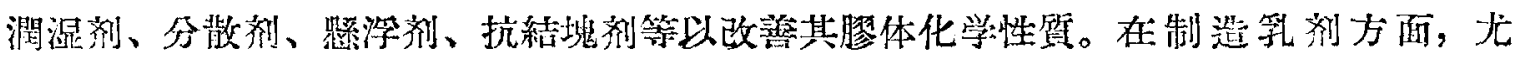

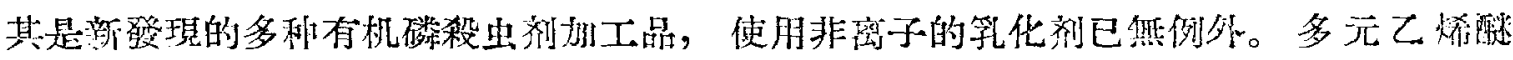
(Polyoxylene)与脂师醇或芳基醇、莱酶的縮合物, 不但可以提高藥欲, 还可以降低对于商

[1] Roller, P.: Agr. Chem. 10(3): 103(195̄5).

[2] Вольфкович, С. И., Н. Н. Мельников, В. И. Орпов: Химическая Промышпенность,1954(6):1. 
等动物的毒力。含有 $40-50 \%$ 的 DDT 或 666 的浱縮碛油筮剂在苏联已撗大生在 粉剂制造方面已多能根据机械（如飛机或地面脚粉器）和䒚效的要求而制成不同細度的

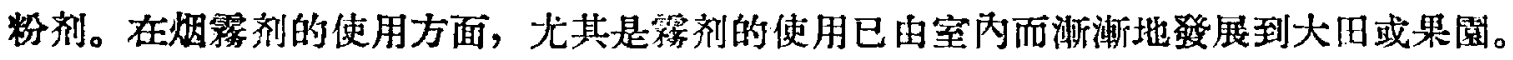
苏联最近在霧化机的制造方面和使用性能力面的呼究有很湍的成就

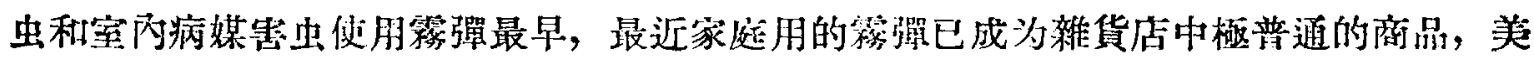

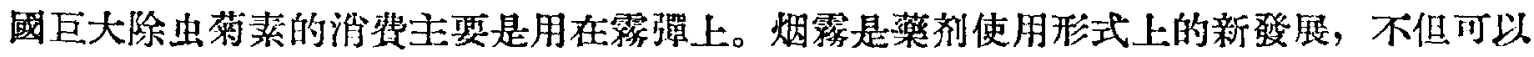

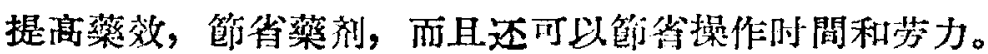

关于藥剂的化学結棈与生物活性的关系, 各國都使用了很大的人力在研究。这类的 問題是最基本的也是最难解决的問題。目前在研究合成新藥剂上仍带有宣目性, 只能合 成出一系列的类似化合物，然后試試看那一种有效，倘不能利用一种規律有日的地合成 符合于某一要求的藥剂。有机磷殺虫剂为最近几年以來發展最快的, 也是从事于研究的

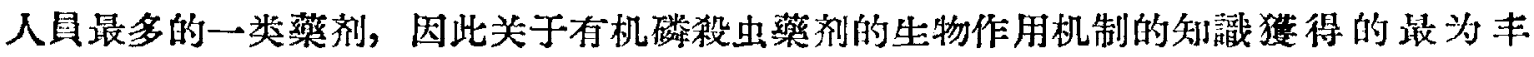
富, 科在实际应用到防治虫害上起了很大的作用 ${ }^{[3]}$ 。在研究各种殺虫剂在生物体內的傳 導、分解或代謝作用上，早于1931年就应用了放射性种酸领來研究虽酸鈴在昆虫体內的

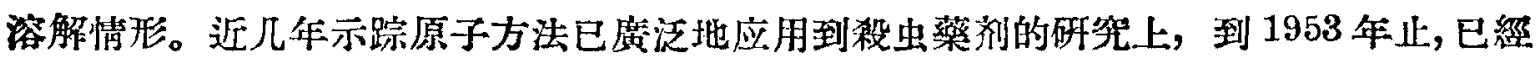
制成手試用了留有示踪原子的有机氯化合物五种（DDT类型的化合物和 666)，存机磷化

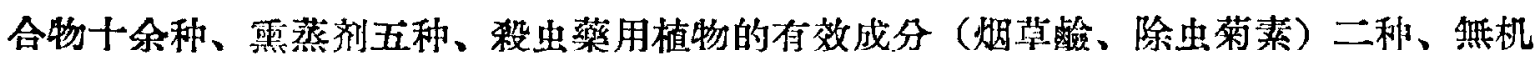
藥剂七种 ${ }^{[4]}$ 。利用示踪原子研究殺虫䒚剂对于生物作用的机制, 給安全使用、改善使 用 方法提供了重要资料。在藥剂分析方法上已采用了最新的仪器分析方法, 如色諳、标新、

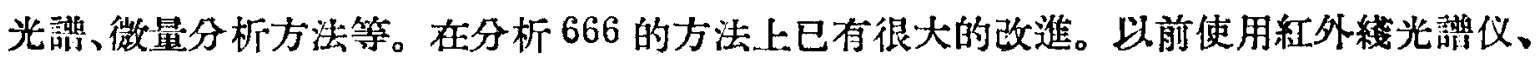

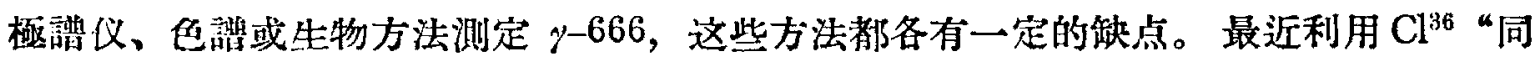

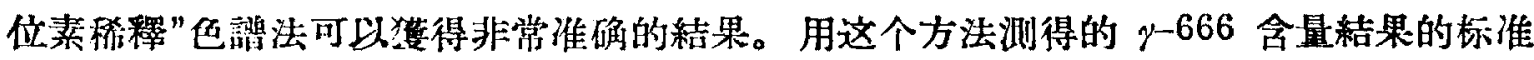
美僅在士0.1 左存 ${ }^{[5]}$ 。

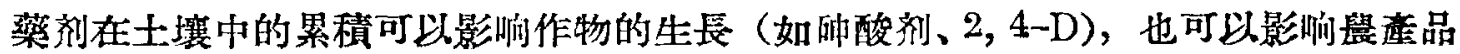
的筫量（如 666 可以給馬鈴薯或花生带爽一种不良的气味)，在食品或飼料中的殘留更

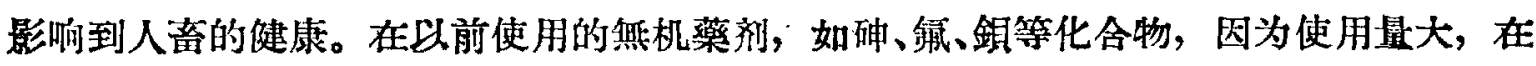
研究这一类的問題上使用一般的分析方法是没有困难的。新兴藥剂如 2, 4-D、有机磷剂、 DDT、666 等，效力大，使用量小，在薬剂殘留問題的研究上，一切旧的分析方法都不 適用了。保証这些高效能藥剂对于人畜的安全，只有徽底明了藥剂在食品中的殘留和分 解的情况, 提出充分的科学根据, 才能作出正确的結諭。

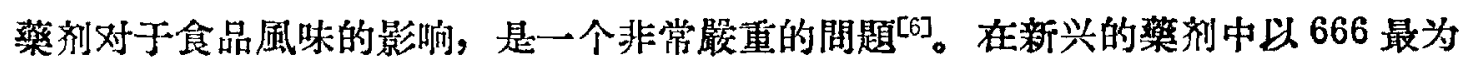

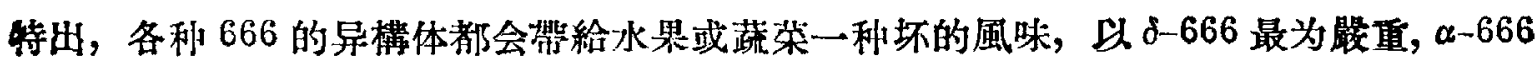

[1] Вопьфкович, С. И., Н. Н. Мепьников, В. И. Орлов: Химическая Промышленность, 1954(6): 1.

[2] Никифорова, А. М.: Аэрозоли, Сельхозгиз (1954).

[3] von Rümker, R.: Agr. Chem. 10(12): 40(1955).

[4] Dahm, P. A.: Soap, 29(9):136(1953); $29(10): 148$ (1953), 29(11):141 (1953);29 (12): 167 (1953).

[5] Craig, J. 'T., P. F. Tryan: Anal. Chem. 25: 1661(1953).

[6] Boswell, V.R.: J. Econ. Entomol. 48:495(1955). 


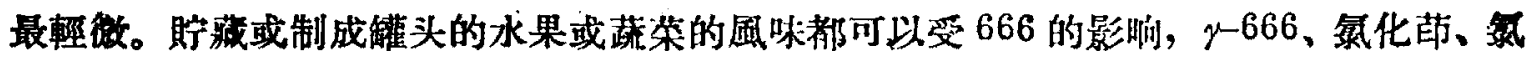
化埮要好些。生長在經 666 处理的土壤的花生和植物堣根的風味都可以受到影响。这类 的研究工作除非經过長时期的試欲才能得到肯定的結諭。在苏咲和美國都限制使用 666 在果樹或濒荣上。

\section{患業藥剂在我國弡展的情况}

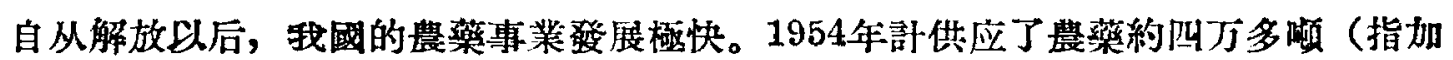
工以后的商品, 包括國廉或進口的, 也包括硫酸釦和硫磺等在內), 超过前㧃年供应量 的总和。1955 年約訢 10 万顿，1956 年可能要达到 1955 年的 5 倍或 6 傍。

从 1955 年的農藥的消费量和 1956 年預定供应量的表面数字看來不算很少, 订是除

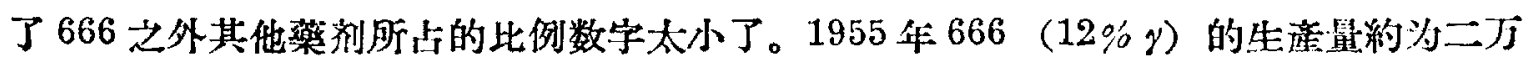
顷，今年生量可能为三四万懒，这个数字䄪等于美国 1950 年的生產量。1955 年除了

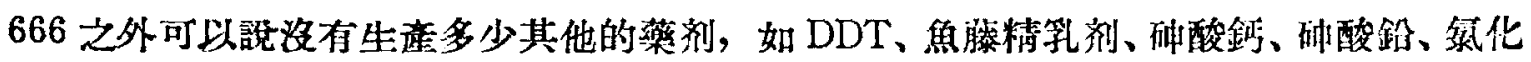
苦、澳甲烷等, 多者不过三四百顿, 少者不过几十瀬, 最常用的配制波尔多液和石灰硫唡 合剂的原料一一硫酸銅、硫磺等, 也不过千獺左右。廣泛使用的有机水剂、E-605、DDT

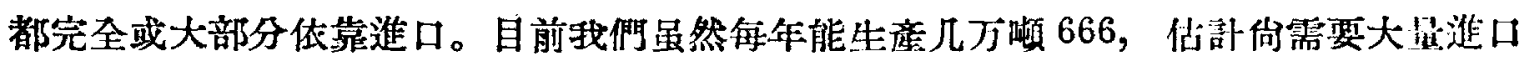
才能滿足 1956 年各地区的姴求。1955-1956 年666 的消费量估計約占㩰刘总量的 $80 \%$ (以加工以后的成品計算), 这样的数字比例是不合理的。履势的形成是因为我們未能

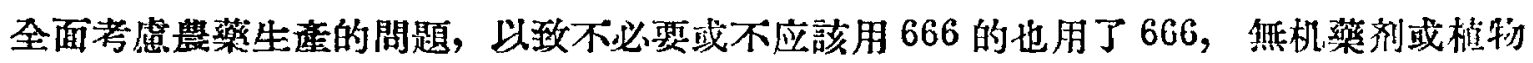

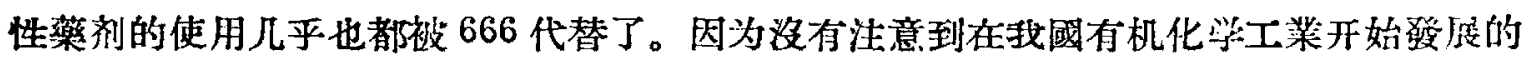

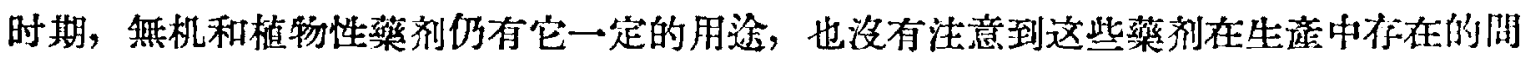

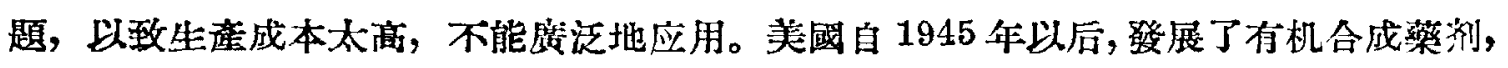
但也不是只發展 666，也發展了其他有机藥剂 (参考前表)。苏联目前也是在發展存机 合成藥剂, 但無机菜剂不是在㺂少而是在坦加, 不过坦加的比例要比有机合成藥剂小得 多。罗馬尼亞早于 1947 年就生了 666 , 但在多腦河地区防治䗷虫仍然用的是本國被的 亞砷酸鉐。樂剂是需要多种多样的, 各有長短, 只有互相調济着使用才能發揮最大的效

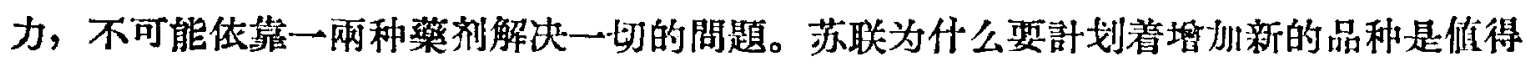

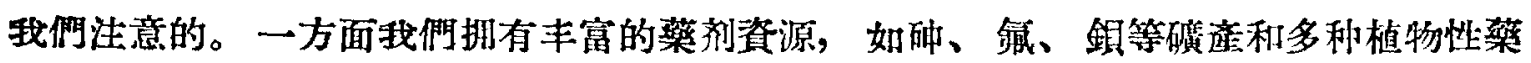

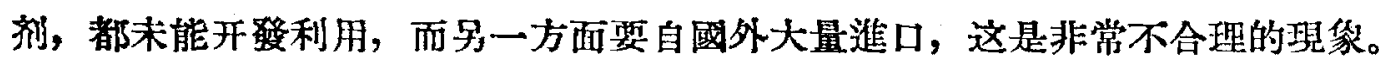

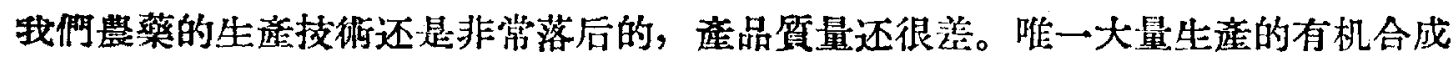

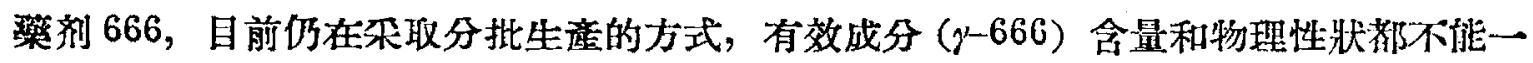
致。有些藥厂的藏品算量很美, 使加工厂在加工上威到困难。其他如 DDT、氮化苦等, 也不是進行正規的生道, 量少, 不能保部一定的翼量。在䒚剂加工的工作中, 遍求生

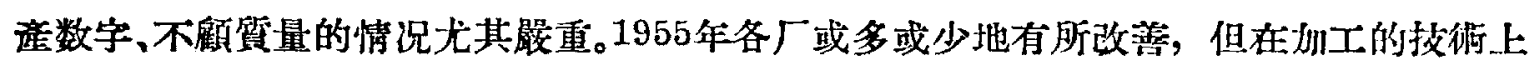
还远远地落在其他國家的后面。一般的加工厂毁不自行作一些田間观察工作，也不重視 蔡剂在实际使用中所發生的問題。

在農菜研究方面我們还沒有基礎。農藥的研究是化学家和生物学家綜合性的工作， 在我國尚末得到有关科学家們的重視, 现只有極少数的人参加这一項工作, 而且多牛是 
作現有藥剂的模仿制造或改進加工过程的工作。系緒的研究僅在磷有机化合物的合成方 面有了一个开始。研究工作的条件非常落后，我們何沒有一个机構有一套比較完整必要 的農藥分析設备, 也沒有一个有条作的䤵力試驗室。至于比较高級一些的研究工作, 如 藥剂的化学結權与生物活性的关系, 藥剂在生物体付的傅導及代謝等問題, 都还沒有進

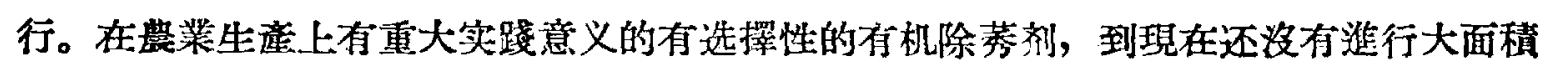
的田間試驗。选擇性除菱剂比使用其他農藥需要较信的技術, 不結合我國的栽培制度、 農作物和雜草的种类進行試驗就很难推廣使用。

\section{農業药剂在我國弡展的方向和今后的趨勢}

農营䒚剂在我國發展的方向也和其他学科一样, 要結合目前情况首先解决在生迹上 存在着的問題，萠足席大農村的要求。同时奶必須根据本学科在科学先淮的國家里發展 的形势，作出長远的研究工作的規划。

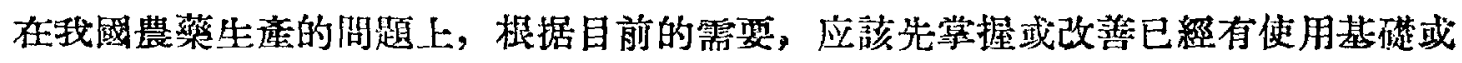

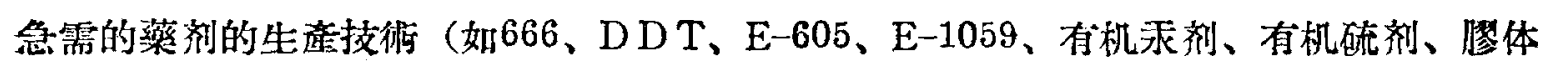
硫、2,4-D、2,4,5- T、氮化苦、磷化鋅等), 同时型充分地利朋有关農桠的一切資源, 包括

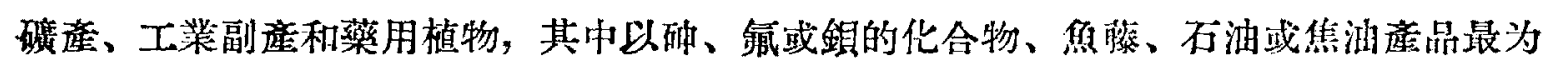

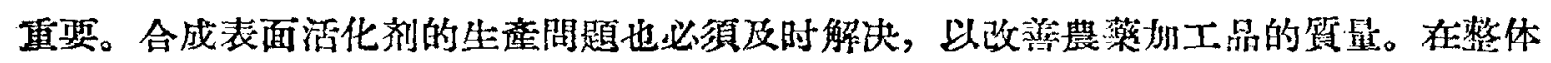
上，应該以提商質量，降低成本，增加必需的新品种，在兩三年內作到自給自足，不再 仰給于國外進口为原則。

有关農藥資源的綜合性的利用問題非常重要。不把資源調查清楚，整理訴价，調整 用途，便很难作出長期的生磨視划。

根据農業㩰剂今后發展的趋势, 有机合成拲剂今后必将占更重要的地位。美國自 1945 年起，有机合成䒚剂發展迅速，目前有机合成藥剂的生裹量約占農藥总生產量的 $80 \%$ 。

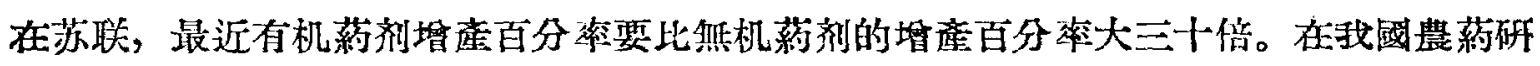
究長远規划中，应該把重点放在有机合成方面。有机合成農蒜的系統研究非常重要，应

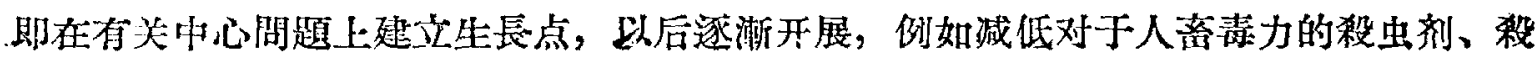

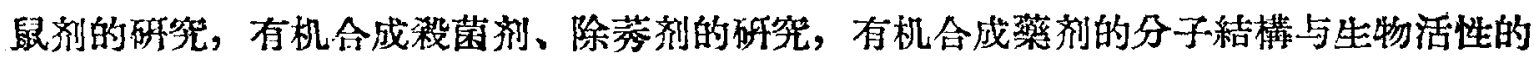
关系、在生物体內的代鲋、在土壤中的絮積、在食品中的殘留等問題的研究，都应列入 長远的研究规划中。

总艺，弡展農業蔡剂科学在我國淤会主义建設中占有很重要的位置。如果这个科学 的發展落在其他学科的后面，将会給國家紫桃很大的損失。我們在这門科学上是没有基 礎的, 从事于呼究工作的入員非常少。因此, 我們必須大力地培养新生力量, 家取有释 驗的化学家 (有机化学、翏体化学、分析化学、生物化学、化学工程) 和生物学家 (微 生物、昆虫、植病）参加这項工作。在研究有关生物学方面的間題上离不了化学家，在 研究有关新藥剂的合成或生严方面的間題上也离不开生物学家。

農業薬剂的研究工作是多方面的，关系錯綜复雜，紹不可能由个別或少数几个机㭗 負担这个重大任务, 有必要建立統一領導制度, 組織人力, 分配任务, 按照規划進行工作。

以上儿点意見，不㿟全面，諽提出供讀者参若。

6 月号科学通报 